Eixo Temático: Educação Não-Formal

ET-08-002

\title{
APLICAÇÕES DE JOGOS DIDÁTICOS NO ENSINO DE BIOLOGIA: UMA PROPOSTA PEDAGÓGICA COM CRIANÇAS HOSPITALIZADAS
}

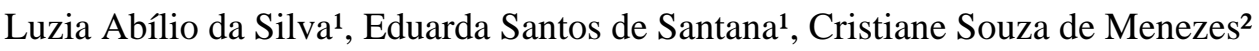 \\ ${ }^{1}$ Lincencianda do Curso de Ciências Biológicas, Centro de Biociências (CB). Universidade \\ Federal de Pernambuco (UFPE). \\ ${ }^{2}$ Docente do Departamento de Métodos e Técnicas de Ensino. Centro de Educação (CE). \\ Universidade Federal de Pernambuco (UFPE).
}

http://dx.doi.org/10.21472/congrebio2016.et-08-002

\section{RESUMO}

A prática de atividades que ajudem na aprendizagem de conteúdos de Biologia tem sido uma preocupação constante para muitos educadores que atuam tanto na educação formal quanto em espaços educativos não-formais. Nota-se que cada pessoa aprende de uma maneira distinta, fazendo com que os professores busquem se preparar para desenvolver diferentes estratégias pedagógicas que estimulem os estudantes a se relacionarem mais facilmente com cada conteúdo apresentado. Os jogos didáticos podem ser uma importante alternativa para auxiliar na construção do conhecimento e aprimoramento do processo de ensino e aprendizagem. Além disso, são dinâmicos, e podem ser desenvolvidos pelos próprios professores e alunos ou facilmente encontrados em comércio local. O objetivo deste trabalho é analisar as contribuições da aplicação de jogos didáticos em um espaço de educação não-formal, apresentando a sua importância para o reforço de conteúdos já aprendidos e para o desenvolvimento da criatividade e da sociabilidade de crianças hospitalizadas. O trabalho foi desenvolvido, com a aplicação de jogos didáticos com conteúdos de Biologia em uma brinquedoteca, implantada por uma organização não governamental em um Hospital da rede pública do estado de Pernambuco referência no atendimento de queimados e em traumatologia. A atividade foi realizada com 9 crianças e 2 adolescentes de várias idades que se encontravam hospitalizada na instituição. Observamos a importância da utilização de jogos didáticos no ambiente hospitalar, contribuindo para o bem-estar das crianças, com melhora em seu quadro clínico, e em sua aprendizagem. Ao destacar a importância de métodos alternativos de ensino, conclui-se que a utilização de jogos didáticos é uma importante ferramenta, pois promove motivação e socialização facilitando a fixação de conhecimentos já estudados e a construção de novos conhecimentos.

Palavras-chave: Jogos Didáticos; Ensino de Biologia; Educação Não-formal.

\section{INTRODUÇÃO}

O jogo pedagógico ou didático é aquele fabricado com o objetivo de proporcionar determinadas aprendizagens, diferenciando-se do material pedagógico, por conter o aspecto lúdico (CUNHA, 1988), sendo uma alternativa para melhorar o desempenho dos estudantes em alguns conteúdos de difícil aprendizagem (GOMES e FRIEDRICH, 2001).

Atualmente os jogos didáticos estão sendo pesquisados e procurados por vários professores e educadores, buscando melhorar o desempenho do aluno nas atividades tanto em sala de aula como fora do ambiente escolar. Os jogos proporcionam uma atividade repetitiva e didática de aprendizagem buscando a fixação e aprimoramento do conhecimento.

Para Piaget (1978) a atividade lúdica auxilia no desenvolvimento do indivíduo, uma vez que a aquisição de regras leva-o a reconhecer seus limites no jogo, à expressão do imaginário, a 
refletir, a expor seu ponto de vista. No jogo o erro ou o acerto leva-o a apropriação do conhecimento. Neste caso, o jogo não é o fim, mas o eixo que conduz a um conteúdo didático específico, resultando em um empréstimo da ação lúdica para a aquisição de informações (KISHIMOTO, 1996).

Além disso, por aliar os aspectos lúdicos aos cognitivos, entendemos que o jogo é uma importante estratégia para o ensino e a aprendizagem de conceitos abstratos e complexos, favorecendo a motivação interna, o raciocínio, a argumentação, a interação entre alunos e entre professores e alunos (CAMPOS et al., 2003).

Reconhecendo as dificuldades que o professor possa enfrentar ao ministrar conteúdos de ciências ou biologia, os jogos apresentam-se como uma alternativa viável e interessante no desenvolvimento do aluno, nas áreas afetiva, cognitiva e psicomotora. Trata-se de um instrumento importantíssimo que pode despertar a curiosidade e o interesse do aluno.

O Jogo é uma atividade com objetivos claros para o desenvolvimento da criança, que constrói, por meio da interação, a percepção futura de mundo do sujeito (ANCINELO, 2006). O brincar é parte essencial do processo de desenvolvimento, não devendo ser visto como atividade complementar ou dispensável, os jogos didáticos fazem parte da brincadeira com capacidade de explorar a imaginação, dando motivo e importância a sua ação.

Acreditamos, assim como Kishimoto (1996), que o professor deve rever a utilização de propostas pedagógicas tradicionais passando a adotar em sua prática aquelas que atuem nos componentes internos da aprendizagem, já que estes não podem ser ignorados quando o objetivo é a apropriação de conhecimentos por parte do aluno. Entretanto, é com pouca frequência que vemos estas estratégias sendo aplicadas nas salas de aula, e seus benefícios ainda são desconhecidos por muitos professores (GOMES e FRIEDRICH, 2001).

Portanto, os jogos didáticos podem ganhar espaço na educação, tanto formal quanto não-formal, de forma divertida, a fim de estimular, motivar e despertar o interesse das crianças a partir de seus conhecimentos prévios sobre assuntos de Biologia, esclarecendo dúvidas e erros frequentes. Além disso, podem ser um método eficaz de avaliação, pois através dos jogos é possível analisar ações e diferentes situações de aprendizagem.

Os espaços educativos não-formais possuem um grande potencial de investigação e descoberta para todo aquele que os visitam. Entre os espaços não-formais de educação mais procurados na área de biologia estão os jardins botânicos e zoológicos. No entanto, há outros que embora não criados especificamente para o ensino de Biologia, se mostram como espaços com potencialidades para o desenvolvimento de processos de ensino e aprendizagem de fatos e conceitos biológicos.

A utilização dos espaços não-formais pode servir como alternativa quando a frequência à instituição escolar fica impedida por problemas de saúde, por exemplo, como ocorre em hospitais nos quais crianças e adolescentes podem ficar vários dias ou meses afastados da escola, prejudicando assim seu desenvolvimento e aprendizagem, ou até mesmo ocasionando o esquecimento dos conteúdos estudados anteriormente.

Durante a disciplina de Estágio em Ensino de Biologia 1, foi possível trabalhar em espaços não-formais de educação e aprendizagem. Dentre eles, uma brinquedoteca instalada em um grande hospital da rede pública do Estado de Pernambuco, referência no atendimento de traumas e de queimados, localizado em Recife-PE.

A brinquedoteca recebe um grande número de crianças e adolescentes diariamente e é um local para que os mesmos possam se divertir, aprender, refletir e pensar sobre o conhecimento, apesar das dificuldades de saúde. Na brinquedoteca os níveis de conhecimento são distintos devido à variedade de idades e grau de escolaridade das crianças e adolescentes.

\section{OBJETIVOS}

Este trabalho tem por objetivo analisar as contribuições da aplicação de jogos didáticos em um espaço de educação não-formal, apresentando a sua importância para o reforço de 
conteúdos já aprendidos e para o desenvolvimento da criatividade e da sociabilidade, enriquecendo o conhecimento de crianças hospitalizadas.

\section{METODOLOGIA}

Os jogos didáticos foram aplicados em dois dias com 9 crianças e 2 adolescentes de várias idades que se encontravam na brinquedoteca enquanto recebiam atendimento hospitalar.

A brinquedoteca foi implantada por uma organização não governamental, que possui vários voluntários se dividindo entre palhaços, humanizadores, brinquedista, administração, equipes de apoio e comunicação, levando alegria ao ambiente hospitalar através de músicas, brincadeiras e jogos.

Nesse local, várias crianças estão em um momento delicado de saúde e provavelmente devido a isso estão também afastadas da escola por um período longo ou curto de tempo, dependendo da gravidade do seu caso, ou seja, o dia a dia no hospital tende a ser bem repetitivo, com medicações intensas, curativos e procedimentos na enfermaria a fim de melhorar o estado de saúde.

Os jogos didáticos aplicados pelas autoras na brinquedoteca foram pesquisados na internet e em livros relacionados à área de ciências e biologia, sendo o primeiro deles o "Jogo do Baralho” (figura 1). Esse jogo encontra-se disponível na internet para download, o que tornou possível para as autoras a sua confecção para aplicação na brinquedoteca com as crianças.

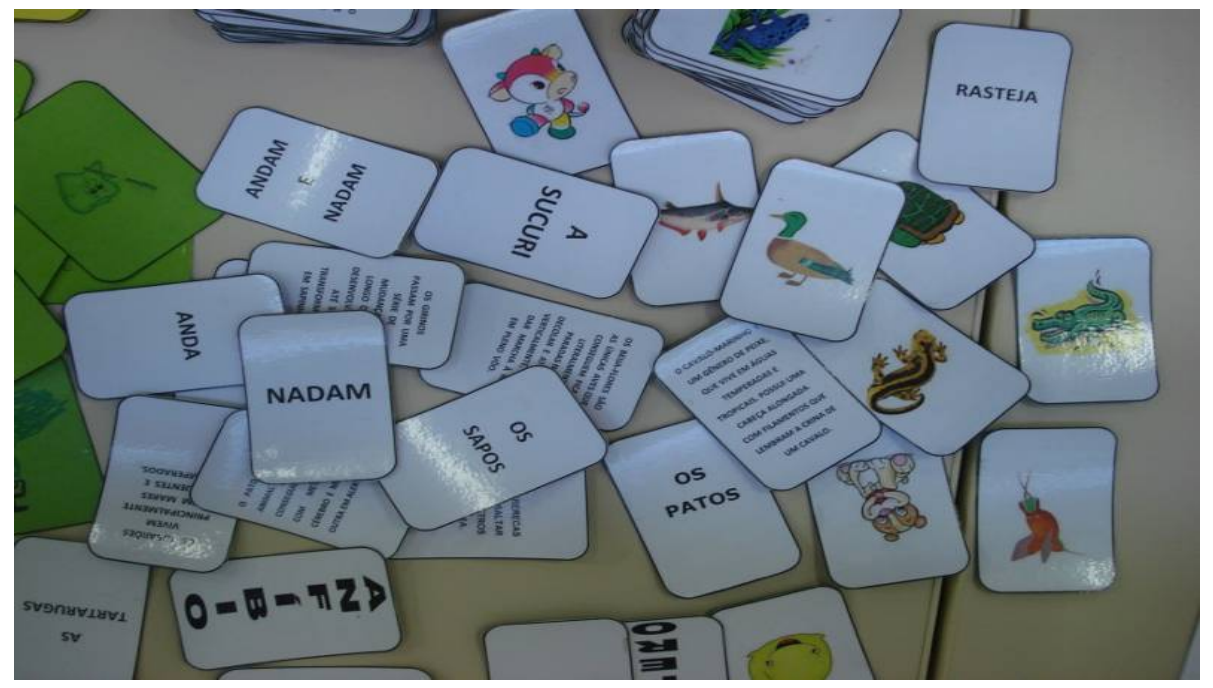

Figura 1. Fonte: https://ensfundamental1.wordpress.com/407-2/jogos-ciencias/

Organização dos jogadores: Dividir a turma em grupos de 4 alunos

Capacidades a serem trabalhadas: Caracterizar alguns animais; Identificar a que classe pertence alguns animais; Conhecer mais informações sobre alguns animais; Elaborar estratégias para formar as trincas.

Material: Baralho confeccionado pela professora ou até mesmo pela turma (papel cartão, retalhos de papel mais grosso para confeccionar as cartas. Figuras ou desenhos de animais, curiosidades sobre os animais).

Desenvolvimento: O jogo consiste em formar trincas seguindo critérios como:

1. Três animais pertencentes à mesma classe. Ex: gato, cachorro, vaca (mamíferos).

2. Formar uma sequência de animal + característica + curiosidade

3. Formar uma sequência de animal + característica + a carta da classe a qual pertence 
4. Formar uma sequência de animal + curiosidade + a carta da classe a qual pertence

5. A carta curinga pode completar qualquer trinca. Só pode usar apenas uma carta curinga em cada sequência.

\section{Etapas:}

- Definir a ordem de jogada dos participantes (sorteio, par ou ímpar, etc.).

- O jogador iniciante distribui 9 cartas para cada participante

- As cartas restantes ficam no monte no centro da mesa para facilitar a "compra" de novas cartas

- O primeiro jogador inicia o jogo comprando uma carta, que poderá ser utilizada ou descartada conforme seu jogo.

- O próximo jogador poderá utilizar a carta descartada ou comprar uma nova carta

- As jogadas se repetem até que um dos jogadores forme três trincas, sendo o vencedor.

Fonte: Fundamental 1 - Assessoria Pedagógica / Adaptação do jogo de baralho chamado PIFE.

O segundo o jogo didático estava disponível na própria brinquedoteca do hospital, o nome do jogo é "Conhecendo o meu corpo" (Figuras 2, 3, 4 e 5).

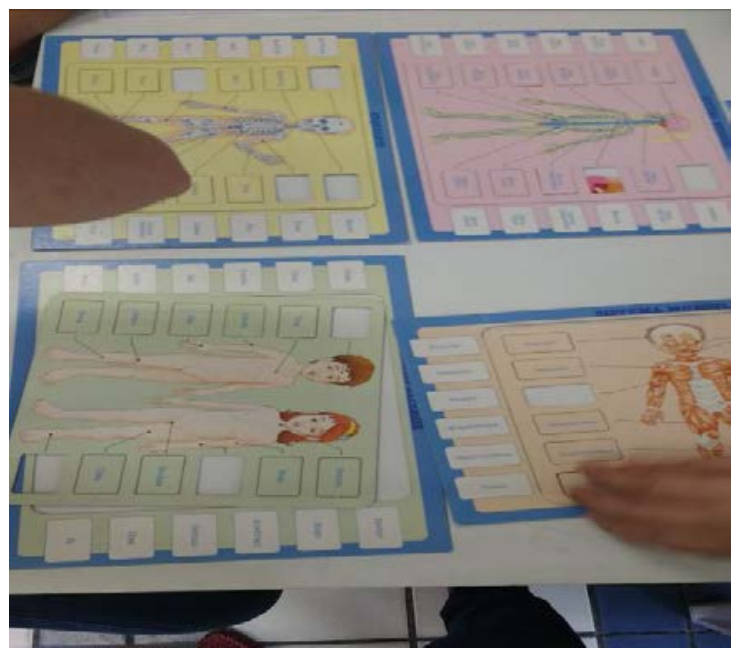

Figura 2

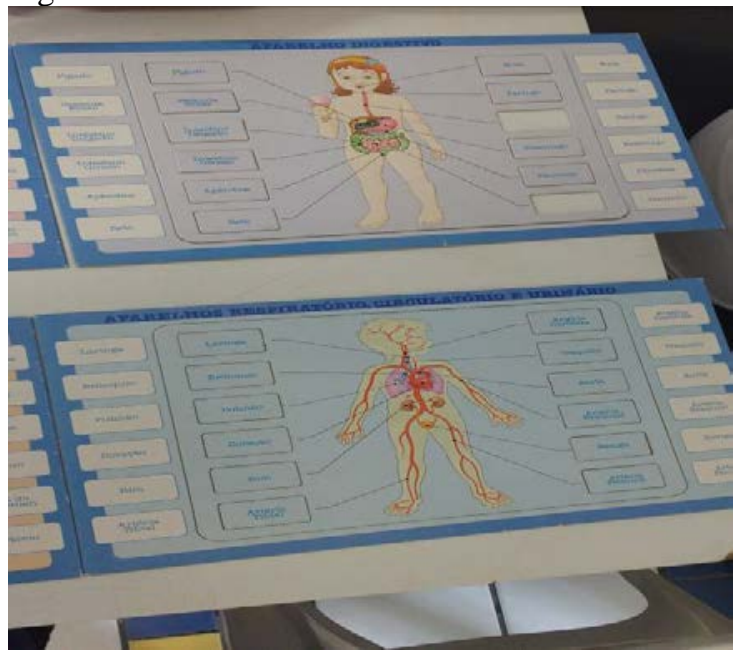

Figura 4

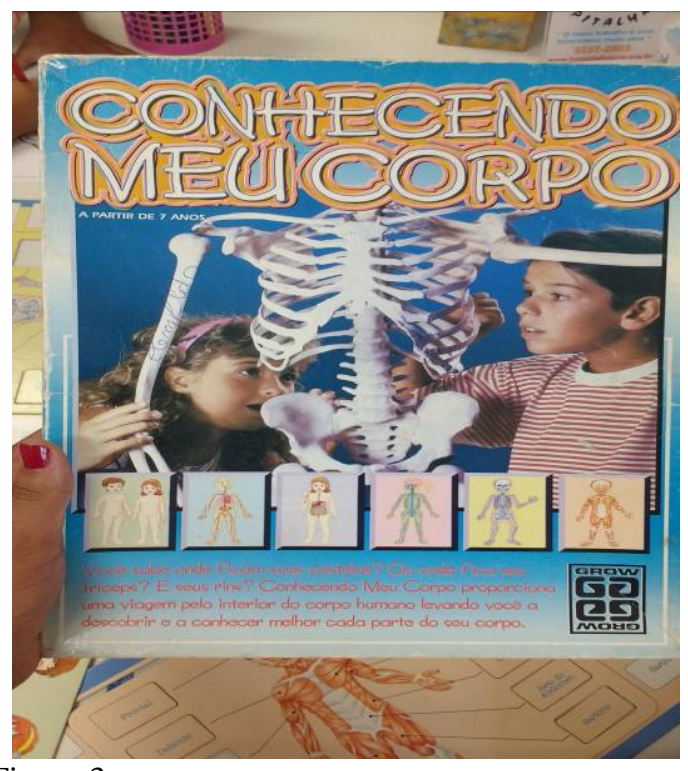

Figura 3

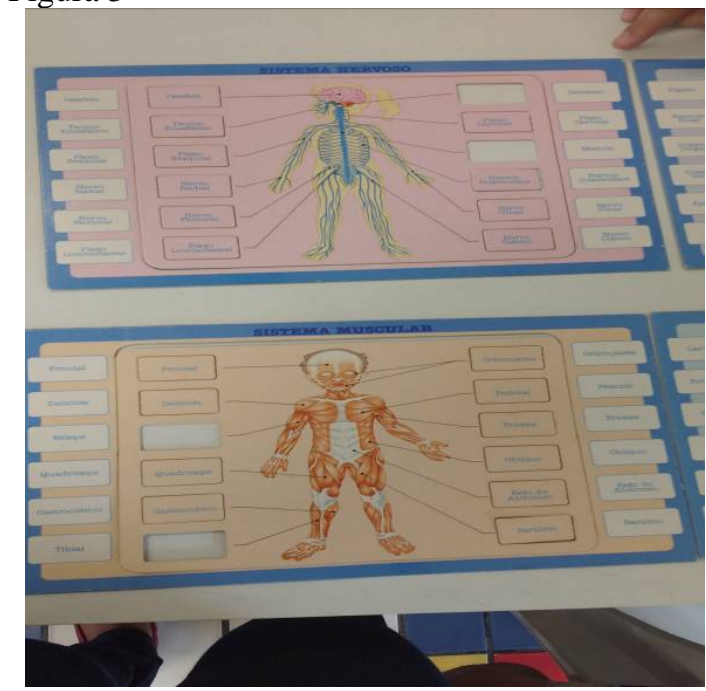

Figura 5 
Organização dos jogadores: Neste jogo é possível colocar 2 a 6 participantes, jogando de forma dinâmica e participativa.

Capacidades a serem trabalhadas: $\mathrm{O}$ estudo do corpo humano (Anatomia humana), análises dos sistemas que constituem o corpo, como o sistema nervoso, muscular, esquelético, digestório, aparelhos respiratórios, circulatórios e urinários.

Desenvolvimento: $\mathrm{O}$ jogo consiste em peças que podem ser encaixadas no tabuleiro. Como possui seis tabuleiros ao todo, cada participante fica responsável em montar um por completo e colocar as peças no local de acordo com o nome que está escrito, por exemplo: No sistema digestório colocar, onde fica a boca, o apêndice, o intestino delgado dentre outros, e seguir colocando as peças corretas nos outros sistemas. Sendo assim, ao terminar de montar todas as peças no fim do jogo conseguimos ver quem levou o maior número de acertos no tabuleiro e foi 0 vencedor.

Esses jogos foram escolhidos para a brinquedoteca por contemplar vários níveis de dificuldade e faixa etária diversificada, estando ainda de acordo com o ambiente hospitalar, pois a maioria dos participantes (crianças e adolescentes) estão pré ou pós operatórios e não podiam correr ou pular em brincadeiras por conta do seu estado de saúde, e por isso, os jogos de mesa proporcionaram uma melhor acomodação.

\section{RESULTADOS E DISCUSSÃO}

Durante as aplicações dos jogos didáticos foram analisados os conhecimentos prévios dos participantes sobre os conteúdos de ciências e biologia, além disso, houve uma apresentação desses jogos no local para que as crianças e adolescentes pudessem participar e também assistir os outros colegas jogar.

Logo após a apresentação demostraram, entusiasmo para conseguir chegar até o fim do jogo. As crianças e adolescentes se sentiram desafiadas a ser o vencedor das brincadeiras, mostrando uma dedicação aos jogos para chegar ao fim, tendo também uma perspectiva de aprendizagem.

No primeiro jogo apresentado, "O jogo do baralho", houve participação de crianças entre 8 e 9 anos de idade, que tiraram suas dúvidas e curiosidades de vários animais contidos nas cartas. Neste jogo a aprendizagem se tornou bastante divertida, pois, a cada erro, surgia uma vontade maior de acertar na próxima vez, e assim cada erro ou acerto na brincadeira ajudou na fixação do conhecimento sobre os animas que aparecem no jogo, enriquecendo o conhecimento dos participantes que também ficaram atentos às características e curiosidades dos animais e seus respectivos parentescos, por exemplo.

Algumas crianças apresentavam dificuldades por não saber ler corretamente, no entanto os acertos eram favorecidos pelas ilustrações apresentadas no jogo. Além disso, foi bem mais fácil acertar as características de animais que faziam parte do seu cotidiano, como cães, sapos e tartarugas, que obtiveram o maior número de acertos no jogo, do que de animais como cobra, baleia e tubarão que estão um pouco fora do cotidiano dessas crianças.

No segundo jogo aplicado o "Conhecendo o meu corpo” várias crianças tiveram o nosso apoio para lembrar das partes do corpo e colocar as peças no devido local, tendo a possibilidade de conhecer a anatomia humana tanto internamente como externamente, através dos desenhos ilustrativos, que apresentava muito bem cada órgão (pâncreas, fígado, pulmão etc...) e partes do corpo (pescoço, genitais, maxilar etc...).

Diante dessa aplicação verificamos que alguns alunos tiveram um pouco de dificuldade nos jogos do corpo humano pelo motivo de poucos saberem os nomes de cada órgão do seu corpo e acabavam desconhecendo as palavras de cada peça. Por isso, foi preciso uma explicação prévia sobre o conteúdo apresentado, incluindo cada parte do corpo humano e sua função. Neste momento a explicação do professor se torna eficaz para responder a dúvidas frequentes e completar o conhecimento adquirido durante o jogo. 
Apesar dessas pequenas dificuldades relacionadas principalmente à capacidade de leitura das crianças (algumas ainda em fase de alfabetização) foi possível observar a importância que os jogos didáticos possuem em locais não-formais de educação para o aprimorando dos conhecimentos, contribuindo para que o aluno aprenda de maneira lúdica, e tenha futuramente melhores resultados em seu desempenho escolar e na compreensão do seu cotidiano e do ambiente que o cerca.

Os resultados deste trabalho com jogos didáticos além de contribuir no ensino e aprendizagem, deixaram as crianças mais a vontade no ambiente hospitalar, contribuindo assim para a melhora do quadro clínico, e para o aprimoramento e desenvolvimento educacional. Além disso, foram avaliados como extremamente positivos pelos profissionais de saúde, pacientes, acompanhantes e familiares.

\section{CONCLUSÕES}

A educação para obter um melhor desempenho no ensino, seja ele ministrado em espaços formais ou não-formais, tem buscado desenvolver e aperfeiçoar metodologias e recursos didáticos, consistindo em práticas inovadoras e prazerosas. Dentre essas temos os jogos didáticos que visam aprender a partir do lúdico. A atividade lúdica pode ser, portanto, um eficiente recurso aliado do educador interessado no desenvolvimento da inteligência de seus alunos, quando mobiliza sua ação intelectual (RIZZO, 2001) aliada a outras capacidades.

Diante disso podemos observar que jogos didáticos são instrumentos valiosos que podem ser eficazes na abordagem de conteúdos de difícil compreensão pelos estudantes. Aulas que utilizam metodologias diferenciadas aumentam o nível de absorção dos conteúdos e autoestima dos alunos. Acreditamos que não existe um método específico para o ensino de ciências e biologia a ser seguido, porém, quanto maior a pesquisa e utilização de métodos variados, maior a possibilidade de interação dos alunos com o universo biológico, além do aprendizado se tornar mais significativo, permitindo que novos conhecimentos se interliguem com os já adquiridos.

\section{REFERÊNCIAS}

ANCINELO, P. R.; CALDEIRA, L. P. O papel dos jogos lúdicos na educação contemporânea. Jornada de Educação, v. 12, 2006.

CUNHA, N. Brinquedo, desafio e descoberta. Rio de Janeiro: FAE. 1988.

CAMPOS, L. M. L.; BORTOLOTO, T. M.; FELICIO, A. K. C. A produção de jogos didáticos para o ensino de Ciências e Biologia: uma proposta para favorecer a aprendizagem. Caderno dos Núcleos de Ensino, p.35-48, 2003.

GOMES, R. R.; FRIEDRICH, M. A Contribuição dos jogos didáticos na aprendizagem de conteúdos de Ciências e Biologia. In: EREBIO, 1, Rio de Janeiro, 2001. Anais..., Rio de Janeiro, 2001, p.389-392.

KISHIMOTO, T. M. Jogo, brinquedo, brincadeira e a educação. São Paulo: Cortez, 1996.

PIAGET, J. A Formação do Símbolo na Criança. Rio de Janeiro: Zahar, 1978.

RIZZO, G. Jogos Inteligentes. 3 ed. Rio de Janeiro: Bertrand Brasil, 1997. 